UDK: 821.111(73).09-31 Делило Д.

\title{
GRAFITI U DELILOVOM PODZEMLJU
}

\author{
VIOLETA STOJMENOVIĆ ${ }^{1}$ \\ Student doktorskih studija Filološkog fakulteta \\ Univerziteta u Beogradu
}

Rad se bavi motivom grafita u DeLilovom romanu Podzemlje. S obzirom na to da se u ovom romanu prikazuju nekolike, za američku popularnu kulturu reprezentativne prakse izrade grafita, rad analizira kontekste u koje in DeLilo smešta, način na koji razumeva estetiku i politiku ovih praksi i njihov odnos prema drugim vrstama stvaralačkih delatnosti, prema kreativnim industrijama i umetničkim formama i žanrovima. S obzirom na to da se rad umetnice Klare Saks predstavlja kao žiža značenja ovih tipova stvaralaštva, posebno se razmatra kako se u romanu predstavlja njihov uticaj na njeno stvaralaštvo i njeno prilagođavanje postupaka i motiva crtača grafita.

Ključne reči: grafiti, avionska umetnost, politika umetnosti, supkultura.

Među mnogobrojnim umetničkim praksama koje je DeLilo rekontekstualizovao u svojim romanima - od klasičnog slikarstva do performansa - nalaze se i grafiti, kojima se u romanu Podzemlje bavi ne samo sa stanovišta estetike formi i žanrova, već i politike i etike umetnosti i stvaralaštva.

Grafiti u roman „ulaze" kroz lik avangardne umetnice Klare Saks i njenu monumentalnu pustinjsku instalaciju, odnosno, kroz intervju koji ona daje i tokom kojeg objašnjava materijalne, ideološke, estetičke, psihološke i druge pretpostavke svog stvaralaštva. Među tim pretpostavkama jeste i istorijsko nasleđe Amerike, pri čemu je jedna od reprezentacija istorije koju ona želi da uključi u svoj rad i slika devojke na trupu jednog od rashodovanih aviona koje koristi kao materijal i podlogu. Reč je o tzv. nose art, odnosno avionskoj umetnosti, grafitima na "nosu" aviona. Ova vrsta slikarstva javlja se od Drugog svetskog rata i predstavlja jedan vid folklora: autor je najčešće anoniman, a njegov rad nezvaničan. Te slike - američki vojni avioni su tokom Drugog svetskog rata i ratova u Koreji i Vijetnamu (iz kojeg potiču i ovi Klarini avioni) bili prepoznatljivi po slikama žena, nasuprot npr. nacističkim slikama orlova i drugih simbola i amblema moći - izražavaju specifičan odnos pilota prema mašinama, deo su specifičnog psihološkog kompleksa koji predstavu o mašini povezuje sa predstavama 0 ženi (Ethell and Simonsen 1991: 8-9; Pfau 2006: 44-56). Oslikavanjem se mašina

1 Kontakt podaci (Email): sloterdajk@gmail.com 
individualizuje, pa čak i personalizuje, izdvaja iz svoje serije, pa su te slike, s jedne strane, uperene protiv uniformnosti. $S$ druge strane, one su znaci identifikacije grupe - u ovom slučaju posade jednog aviona, koja postaje jedna distinktivna zajednica, sa sopstvenim repertoarom znakova. Putem slike, posada izražava svoj emocionalni odnos prema mašini - kult aviona, naročito vojnog aviona koji užitak u riziku, čak strahu, povezuje sa svešću o sopstvenoj destruktivnoj moći, i mitologizacija letačkog iskustva i brzine, jedan gotovo atavistički odnos prema mašini, implicirani su u potrebi da se baš taj avion markira kao svoj, kao deo sopstva, a ne kao puko sredstvo. Grafiti ne samo da manifestuju neraskidivo jedinstvo ljubavi/obožavanja i straha povezano sa korišćenjem smrtonosne tehnologije; oni su i jedna vrsta amajlije, što se u samom romanu vidi iz umetnutog fragmenta - jednog od onih "odabranih" iz privatnog i javnog života, reprezentativnih za atmosferu pedesetih i šezdesetih ${ }^{2}$ - kojim se prenosi razgovor posade baš tog aviona o kojem Klara govori u intervjuu. I ona sama funkciju grafita tumači na isti način: „Taj zalog sreće, taj znamen protiv smrti.“ (DeLilo 2007: 81)³. Avionski grafit ističe kolektivni nad individualnim identitetom - tu poziciju preuzima i Klara jer, iako rad na avionima objašnjava uz pomoć jednog ličnog iskustva, ona to objašnjenje smešta u određenje kolektivnog rada i zajedničkog cilja: „reč je o želji da napravimo prestup i tako se obznanimo svetu, da pokažemo ko smo. Onako kao što su to činili umetnici koji su ukrašavali nos aviona, ili oni koji su na trupu crtali pin-ap devojke." (80)

Oslikavanje aviona bio je tolerisan prestup, upravo zato što se uzimao u obzir psihološki, kompenzatorsko-terapeutski značaj tih slika za pilote. Slike devojaka i žena čine zaseban korpus u okviru avionske umetnosti iz kojeg je DeLilo izdvojio jednu od onih na kojima žene nisu preteće i razmetljive, nisu super-heroine, već su prikazane $s$ dozom nostalgije za mirnodopskim vrednostima oličenim u idealu žene koji Klara prepoznaje u liku i pozi „Dugonoge vitke Sali“ (grafitu po kojem odlučuje da nazove svoje delo): „kao da ambiciozno pozira za pin-ap fotografiju - mada je pri svemu tome delovala i pomalo nespretno" $(80)^{4}$. Putem ovakvih slika, avion se feminizuje a prema njemu se uspostavlja snažan emocionalni odnos koji ne isključuje san o kontroli i dominaciji nad podatnom ženom (Ethell and Simenson 1991: 9). Iako su crtači grafita koristili, kao predložak, manje ili više verno prenete, gotove slike, slike iz časopisa, stripova, kalendara, dakle, vizuelni material koji im je već ponudila industrija zabave, kao otelovljenje fantazma, predstave zavodnica vrlo često su bile supstitucija realne i realistične čežnje za domom, ženom, devojkom ili, čak, majkom (Pfau 2006: 55-56). Ta se čežnja implicira i kroz Klarin opis grafita. Po njoj, reč je o običnoj devojci, možda konobarici (81), koja kao da bi htela da podražava izazovnu pozu modela koji su se u datom trenutku devojkama nametali kao ideal i ženskog i ženstvenosti i kao predmet zavisti i želje. Ovo „kao da“ je presudno za razumevanje razloga koji Klaru navode da

2 U pitanju je treći fragmenat šestog triptiha VI poglavlja, datiran 1. 12. 1969. Deo razgovora dvojice pilota tiče se, između ostalog, i grafita na njihovom bombarderu po kojem će Klara nazvati svoju instalaciju u pustinji. (DeLilo 2007: 616-626)

3 Svi navodi iz romana dati su prema ovom izdanju. U nastavku će se u samom tekstu navoditi samo brojevi stranica u zagradi.

4 I kasnije se, iz perspektive anonimnog pripovedača, potvrđuje ovakva interpretacija figure koju grafit predstavlja: „kao da bi želela da deluje seksi ali nije sigurna da zna kako, veoma svakidašnjeg izgleda“ (617). 
Dugonogu Sali sačuva u svom projektu. Da li je nespretnost intencionalna ili posledica crtačeve neukosti, Klaru očigledno ne interesuje - za nju je ona svedočanstvo da slika ne priziva ni idealizovanu, ni hipertrofiranu, ni zastrašujuću ili preteću ženstvenost, već svet snova i čežnji obične devojke (u svetu koji ne prestaje da konstruiše i da nameće vizuelne uzore ženstvenosti, koliko i muževnosti, ljubavi i svega drugog). Međutim, Dugonoga Sali je još dublje uronjena u svakodnevicu i popularnu kulturu - time što odlučuje da svoje delo tako nazove, Klara u stvari ponavlja gest samog crtača, koji je svoju sliku nazvao po istoimenoj pesmi Litl Ričarda, koja je bila veliki hit. U samom romanu se postavlja pitanje koliko nespretna izazovnost kao pin-ap devojke odgovara Dugonogoj Sali o kojoj peva Litl Ričard. Ubrzan, čak frenetičan, razuzdan i žestok ritam te pesme, uz aluzije na preljubu ${ }^{5}$, i činjenica da pesma potiče iz pedesetih, iz vremena kada se rokenrol suprotstavlja mnogim društvenim konvencijama i omladini nudi jezik i ritam bunta (Torg 2002: 93-96), kao da podržavaju stav jednog od pilota tog aviona, Luisa, u čijoj verziji je Sali opaka i opasna crnkinja. Njegovo negodovanje zbog izgleda devojke koja je naslikana na trupu aviona i nazvana po liku iz pesme jednog crnca u stvari je opiranje belačkim modelima ženstvenosti. To je i isticanje svačijeg prava da u lik uzbudljive i odvažne lepotice projektuje sopstvene predstave o lepoti, privlačnosti, seksipilu. Očigledno je, dakle, da je pretpostavljena "stvarna" Sali nešto sasvim različito za Luisa iz šezdesetih i za Klaru iz devedesetih godina dvadestog veka. Stoga, kada odluči da svoje delo nazove po toj ženi i mladićima kojima je ona bila inspiracija i amajlija, a koje ona može samo da konstruiše u mašti, Klara u svoje delo ugrađuje i borbu rasnih i rodnih konstrukcija, jer je i ona deo svakodnevnog života kojem je njena instalacija zapravo posvećena ${ }^{6}$.

Pored avionske umetnosti, grafiti iz podzemne železnice jesu druga Klarina autopoetička referenca. Ona lično svoj način rada smatra analognim „instinkt[u] crtača grafita" (80), čime se ukazuje na to da je njeno delo, bez obzira na zvanične dozvole koje ima da ga sprovede, ipak prestup, kao što su to bili i grafiti iscrtavani po vozovima njujorškog metroa sredinom sedamdesetih7, kao "gerilski", a po vlastima, i vandalski način obeležavanja javnog prostora novim tipom znakova i kao vid pobune protiv zvaničnih i regulisanih sistema označavanja i imenovanja ${ }^{8}$. Kako će čitalac kasnije saznati, Klara u tom trenutku na umu ima vrlo konkretne grafite. U poglavlju "Cocksucker Blues" ona, zajedno sa vlasnicom galerije koja je i njen izlagač, pokušava da pronađe misterioznog Munmena 157, čija dela galeristkinja Ester želi da izlaže. Esterina iluzija da će grafiti naslikani na zidu, koji će ona "dati" Munmenu biti isto što i site specific grafiti, komična je, ali i simptomatična. Njome se otkriva mehanizam odbrane dominantne kulture od supkulturnih ispada iz postojećih sistema znakova i (razmenskih) vrednosti, zbog čega se Esterino oduševljenje grafitima pojavljuje

5 Videti, na primer: http://www.youtube.com/watch?v=kc92Mby07wE.

6 Up. „A ja želim da taj život [neke prave i izvorne Sali, tvorca pesme o njoj, onoga ko je oslikao avion, posade koja je njime letela] postane deo našeg projekta. [...] ja hoću da naše namere ostanu svedene i sasvim ljudske uprkos ogromnom poslu koji smo obavili i velikom poslu koji je još pred nama" (81).

7 Njujorški grafiti su deo supkulture koja se javila šezdesetih godina dvadesetog veka i postali uzor sličnim oblicima verbalno-likovnog izražavanja u javnom prostoru širom sveta. (Sulima 2005: 69)

80 pojavi grafita kao o „pobuni znacima“ protiv „semiokratije", vladavine kodova i znakova koji determinišu modele ponašanja za svako mesto i svaki trenutak, detaljnije govori Bodrijar (1991: 91-99). 
u kontekstu tendencije ka sveopštoj komoditizaciji - da se svemu odredi tržišna i simbolička vrednost, da ništa ne ostane van tokova razmene. Klara, ipak, kreće sa njom u uzaludnu potragu za Munmenom. I ovog umetnika upoznajemo prvo posredno, kroz priču o njemu i kroz Klarino viđenje njegovih grafita, a zatim i na delu, pri čemu je fragmenat o njemu umetnut, poput intermeca, u prikaz projekcije Ajzanštajnovog filma, tako što se prelaz sa jedne scene na drugu vrši uz pomoć zvuka voza, Munmenovog „platna" i sredstva izražavanja. S obzirom na to da su autori grafita u periodu o kojem je reč bili, kao i sam Munmen, uglavnom predstavnici imigranata i drugih manjinskih i diskriminisanih grupa, ova vrsta "vandalizma" predstavljala je ne samo izraz otpora i provokacije sistema od strane mladih, kao u slučaju drugih omladinskih supkultura, već i vrstu političkog protesta. Grafiti su ovde znaci kojima se obznanjuje svoje postojanje i time ogoljava uslovnost, restriktivnost i selektivnost javnog i javnosti. Ti su se grafiti razvili iz stilizovanih, često vizuelno i koloristički vrlo napadnih potpisa, tzv. tagova, a ti potpisi su, kao i Munmenov, zaista bili komponovani iz nadimka / pseudonima i naziva tj. broja ulice i iscrtavani / ispisivani po spoljašnjim i unutrašnjim zidovima vozova podzemne železnice. Munmen, kao pseudonim Ismaila Munjosa, trebalo bi da bude ironija na račun težnje ka osvajanju kosmičkih prostora i tadašnjeg nadmetanja između Amerike i Rusije u sletanju na Mesec; ironija kojom se ukazuje na to da je za običnog građanina Njujorka, čovek iz tunela podzemne železnice, ili iz geta, jednako stran i dalek, odnosno, u svetlosti pohoda na Mesec, jednako zvanično nepostojeći kao i čovek sa Meseca.

„Bombardovanje“ voza, kako se u žargonu ova delatnost naziva, označava zaposedanje javnog prostora i otpor administraciji informacija i upravnom sistemu grada, jer se natpisi nadmeću sa zvaničnim obaveštenjima, upozorenjima i drugim znacima za informisanje građana, potiskuju ih ili prekrivaju.

Ispisivanje grafita narušava hegemoniju korporacijskog/upravnog stila nad urbanim okruženjem i nad svakodnevnim situacijama. Ono je forma estetske sabotaže, prekida prijatnu i dostatnu uniformnost "planskog" gradskog prostora i predvidivog načina života u gradu. Za crtače, grafiti remete življeno iskustvo masovne kulture, pasivnost potrošnje. (Farrell 1996: 176) ${ }^{9}$

S jedne strane, identitet se lažnim imenom skriva, a sa druge, predstavlja kao "teritorijalan", kao određen mestom boravka, dok se vizuelnim aspektom prema tako konstruisanom liku uspostavlja određeni odnos. Crtač sebi dodeljuje simbolično ime i tim gestom se odriče imena koje ga vezuje za poreklo. Promena identiteta kao „socijalna proklamacija" jeste javno konstantovanje, tačnije, nametanje jednog novog identiteta (Arden 2007: 77). U slučaju tzv. divljeg stila crtanja (wild style), koji dovodi do krajnjih konsekvenci mešanja slova i slike, grafičkog i likovnog - a prema onome što se u romanu govori o Munmenovom potpisu, on jeste predstavnik ove struje - odnos prema

9 "Graffiti writing breaks the hegemonic hold of corporate/govermental style over the urban environment and the situations of daily life. It's a form of aesthetic sabbotage, it interrupts the pleasant, efficient uniformity of "planned" urban space and predictable urban living. For the writers graffiti disrupts the lived experience of mass culture, the passivity of mediated consumption." 
imenu, kao simboličan izraz odnosa prema identitetu, još je jače istaknut nečitljivošću i dinamikom ostvarenom kroz odnos boja i linija, na takav način da se stvara utisak kretanja slova. Štaviše, Munmenova slova poseduju radikalnu figurativnosti figuralnost, antropomorfizovana su, tj. u Klarinoj verziji, „humanoidne karikature" (403): ona se znoje, krvare, plešu, sviraju, dišu, jedu i spavaju (441). U njih su pretočeni svakodnevni život, intima, problematična seksualnost, snovi i tegobe njihovog autora. Ona nisu samo jedan od proizvoda tzv. ulične umetnosti nego su otelovljenje karakteristika života ulice i na ulici. Crtač se izražava kao predstavnik svoje ulice ${ }^{10}$, a s obzirom na to da su ulice, četvrti, naselja i sl. u gradovima često rasno, nacionalno, klasno određeni, korišćenje broja još više potcrtava političku prirodu ovog gesta - za grad u kojem živi, taj crtač je bezličan broj. Taj vandalski gestje jedini način na koji on može da komunicira sa drugim gradskim kulturama (Šuvaković 1999: 112) - crtači osećaju da nemaju mogućnosti, a možda ni prava na kretanje, i u doslovnom, i u smislu klasne migracije, kao i to da su prilično uskraćeni kada su informativna i komunikaciona sredstva u pitanju $^{11}$. U liku DeLilovog Ismaila svest 0 odnosu identiteta, prava i mesta je prilično jasna. Stoga, izbor vozova kao prevoznih sredstava koja povezuju čitav grad označava simbolično kretanje autora i dela ${ }^{12}$, njihovu virtualnu sveprisutnost, kao opomena i pretnja: „[U]laziš ljudima u svest i vršiš nasilje nad njihovim očnim jabučicama." (443) Ideja 0 „nasilju nad očnim jabučicama", o manipulaciji recipijentovim / konzumentovim fiziološkim vizuelnim aparatom, jeste nešto o čemu je početkom šezdesetih razmišljao, povodeći se za naučnim otkrićima, i reklamni agent Čarls ${ }^{13}$, idejni tvorac reklamne slike za sok od narandže koja će se, na kraju romana, pojaviti kao podloga kolektivne vizije lika nasilno preminule devojčice (koja bi mogla biti i još jedno delo vandalske estetike Ismaila Munjosa, s obzirom na to da je devojčica bila stanovnik njegovog geta, a da je sok od narandže bio sredstvo uz pomoć kojeg je policija nekada čistila vozove od njegovih grafita). Time što povezuje način razmišljanja jednog mladog i gnevnog beskućnika i jednog uspešnog reklamnog agenta, DeLilo skreće pažnju na način na koji supkulture preuzimaju strategije proizvođača potrošačke kulture i pretvaraju ih u sredstva sopstvene borbe za opstanak i vidljivost, pri čemu njihova subverzija ogoljava i nasilnost prividno nenasilnih praksi advertajzinga. Kao i crtači grafita na avionima, i ovi crtači su vrlo često posezali za vizuelnim sredstvima masovne kulture, tj. za tipografskim rešenjima dizajnera reklama ili crtača stripova, što je još jedan primer popularne upotrebe gotovih predstava i referencijalnih okvira, kako ovu praksu vidi De Serto (De Certeau 1984: 17-18).

Klara, dakle, svoj rad povezuje sa kreativnim i inovativnim, subverzivnim, neovlašćenim upotrebama masmedijskih i drugih serijski i industrijski proizvedenih

10 „Smisao Munmenovog potpisa bio je u tome što su ta slova i brojevi pričali priču o životu ulice.“ (442)

11 Ovaj moment je u Podzemlju dat kasnije, u vezi sa ubistvom devojčice iz geta i njenom slikom, i to na groteskno-ironičan način: stanovnici Ismailove četvrti gledaju televiziju na biciklu, tj. koriste ljudsku snagu da proizvedu neophodnu električnu energiju.

12 Za De Sertoa su upravo njujorški crtači grafita adekvatan primer retorike „hodanja" - figura putem kojih se vrši distorzija, elidiranje ili neka druga transformacija prostora u idiosinkratičnu, nezvaničnu putanju. (De Certeau 1984: 102)

13 "Svetom upravlja onaj ko ima kontrolu nad našim očnim jabučicama” (540) kaže Čarls svom sagovorniku, navodeći i skrivene senzore i kamere uz pomoć kojih se prati reakcija oka na određene boje, oblike i šare, kao sredstvo moguće manipulacije uzbuđenjem i oduševljenjem kupaca. (541-542). 
simbola, i to objašnjava prestupnički karakter njenog dela - vojni avioni iz njene instalacije postaju nosioci oprečnih poruka kojima se prekida njihova do tada "prirodna" veza sa drugim predstavama vojne i oružane moći Amerike. Pored toga što je doživljaj Munmenovih grafita jedan od ključnih elemenata u Klarinom otkrivanju ili ponovnom otkrivanju boje, on doprinosi i njenoj revalorizaciji hiperbole, stvaralaštva koje se ne kloni veličine, ekspresivnosti, snažnih gestova, prkosa, izazivačke samoobjave, rizika. On je, takoreći, vodi od kamerne intimnosti dela nastalih od vlastitih starudija i otpadaka, do rada sa materijalnim manifestacijama ideološkog otpada na jednom od smetlišta istorije.

Krajem osamdesetih i u devedesetim godinama dvadesetog veka, Munmen više ne postoji - Ismail više ne iscrtava vozove, nego Zid - ruševinu tj. otpadak građevine savremen jednom drugom, u romanu nespomenutom otpatku - tada srušenom Berlinskom zidu - a koji se nalazi relativno blizu nerazrušivom zidu finansijske hegemonije, Vol Stritu. Novi vid kritičke delatnosti, novi kontekst i novi stil - posledica komercijalizacije čitave hip-hop i njoj srodne kulture, koja je izgubila svoju stvarnu provokativnost i autentičnost - sastoje se iz crtanja ogromnih murala, likova dece koja su u Ismailovom getu preminula zbog nasilja i bolesti, sa njihovim imenima i datumima rođenja i smrti, kao na nadgrobnom spomeniku (koji ta deca sigurno nisu dobila). Ritam pojavljivanja ovih grafita reprodukuje ritam umiranja, pa je, kao kontekstualno stvaralaštvo, „čin umetničke intervencije u gradskoj sredini [koji] modifikuje internu temporalnost" (Arden 2007: 127). Ovi novi grafiti takođe su znaci postojanja ${ }^{14}$, napadno, veličinom i jarkim bojama, objavljuju svetu kako to da su određene, „nezvanične" ličnosti postojale i nestale bez ijednog drugog traga, tako i to da se tu dešavaju načini umiranja koje većina ignoriše. Oni su memorijalnog karaktera, ali i parodično-groteskni. S jedne strane, deca su predstavljena kao anđeli, sa krilima, dok je njihov pol prikazan uz pomoć najtrivijalnijih stereotipa - muške plave i ženske roze boje. Na prvi pogled - kič. Ili, možda, slike na tragu pop-art odnosa prema potrošačkoj kulturi. U stvari, način na koji se život i smrt u getu ispoljavaju kroz te portrete nije naivno podražavanje ili reprodukovanje klišea, već groteskno izobličavanje reklamnih strategija - velike razmere, jarke boje, oštri kontrasti - vizuelni stimulansi koje pogled teško da može da zaobiđe. Povezivanje umiranja dece sa prepoznatljivim znakovima potrošačke kulture - brendovima, stilovima odevanja, tipovima proizvoda koji su namenjeni mnogo imućnijim i zaštićenijim slojevima stanovništva i koji postoje jedino u reklamnom kontekstu - ima uznemirujuće efekte. Anđeo u najk patikama kao da se obraća svetu u kojem se predstava o Raju ili raju izjednačila sa finansijskim blagostanjem i posedovanjem.

Na delu je, dakle, svojevrsno prisvajanje znakova, predstava, ideja koje su se već ukorenile u kolektivnu svest, postale spontano prepoznatljive, i njihovo ironično izvrtanje i rekontekstualizovanje. Uz poigravanje polisemičnošću reči i slika, ovo je strategija predstavljanja čije se nekolike varijante i mutacije prepoznaju na više mesta u romanu, pa ih je potrebno međusobno uporediti. Tako je, na primer, u jednom slučaju reč o marketinškom triku, o kondomu sa natpisom „Čekaćemo ih na plažama“ (114)

14 Znakovi postojanja su jedan od funkcionalnih tipova grafita (pored znakova delovanja i znakova identifikacije). Detaljnije u Sulima (2005: 71). 
što je aluzija na Čerčilov iskaz od istorijskog značaja ${ }^{15}$, kome se, na ovaj način, pridaje seksualna konotacija. Naslućuje se blasfemičan spoj ubijanja i seksualnog čina, čime se odbacuje obavezujuća ozbiljnost i neprikosnovenost zvanične istorije koja je pomenuti Čerčilov iskaz zabeležila, sačuvala i označila u kontekstu borbe protiv nacizma. Čarlijevi „kreativci" sa idejom da veštačko đubrivo reklamiraju kao „bombardovanje" travnjaka uz pomoć ličnosti i lika stvarnog masovnog ubice-bombaša (538) drugi je primer ovog slobodnog, ludičkog, relativizujućeg i neodgovornog odnosa prema sferi znakova, slika, simbola. U oba ova slučaja, sama ideja o provokativnom i šokantnom korišćenju određenih kolektivnih znanja i nasleđa ne razlikuje se, na prvi pogled, od Ismailovog načina korišćenja njegovom svetu tuđih i međusobno neuskladivih znakova. Ta prividna sličnost potcrtava koliki je značaj socijalne i ideološke pozicije stvaralaca i stvaralaštva u određivanju prirode i smisla dela u savremenom svetu. Autentičan „instinkt crtača grafita“ nema dekorativnu ili marketinšku nego političku funkciju koja ga u polju stalne cirkulacije slika odvaja od drugih praksi stvaranja vizuelnih pastiša, citata, parodija ili aluzija.

Prikazujući neke transformacije jednog tipa odnosa prema tzv. javnom dobru i javnom prostoru, odnosa koji se u romanu javlja u vidu avionskog grafita s početka šezdesetih, integrisanog, poslenekoliko decenija, u umetnički projekatKlare Saks, grafita u njujorškom metrou sredinom sedamdesetih, grafita na zidu koji, s kraja osamdesetih i početkom devedesetih godina dvadesetog veka, odvaja i obeležava geto u Njujorku, DeLilo zapravo izdvaja određena područja koja bismo mogli označiti kao liminalna ${ }^{16}$ ukazujući na kritički potencijal onoga što je istovremeno i unutar i izvan društvenih sistema, negde između kolektivnih pamćenja, potiskivanja ili zaborava i istorije koja je ova liminalna područja proizvela kao svoje sramno naličje (kao potencijalno opasan otpad ili kao „šugu“ u istoimenoj dečjoj igri). Ismailov Zid i Klarinu pustinju - kao mesta ispoljavanja transformisanog „instinkta crtača grafita“ u poslednjoj deceniji dvadesetog veka - DeLilo konstruiše kao dva različita spoja aktivizma, kolektivizma, supkulturnih praksi i kontekstualne umetnosti, da bi prikazao neke procese stvaralačkog i estetskog reagovanja na potiskivanje, poricanje, maskiranje ili prećutkivanje društveno-političkih zala, ostvarive u oblastima liminalnog.

15 U pitanju je parodična aluzija na završnicu jednog od čuvenijih Čerčilovih ratnih govora, poznatog kao „Borićemo se na plažama“ (Churchill 1940), na retoričku virtuoznost tog paragrafa zasnovanog na ritmu, sintaksičkom paralelizmu, anafori i gradaciji, upotrebljenim s namerom da se probude i osnaže nacionalno jedinstvo i savezništvo u borbi protiv nacističke okupacije posle Dankerka.

U originalu Podzemlja, aluzija na ovu (retoričku) borbu glasi: „Nosićemo ih na plažama“" ("We shall wear them on beaches") (Delillo 2011: 111) dok je autorstvo samog iskaza dvosmislenije jer, iako se u prethodnoj rečenici opisuje kako Brajan razgleda kondome sa natpisima, nije sasvim sigurno da on čita jedan od njih: "He did a little Churchill" moglo bi da označava Brajanovu improvizaciju na temu kondoma.

16 Termine „liminalno", „liminalnost" (od lat. limen - „prag") razradio je, na temelju Van Genepovih inicijalnih istraživanja obreda prelaza, antropolog Viktor Tarner. Liminalne oblasti jesu oblasti prelaza (pojedinca, neoficijelne zajednice...) u novo stanje, tako da se za njih vezuje neodlučivost i neizvesnost, jer se ne može ustanoviti da li će doći do reintegracije u sistem ili do trajnog otpadništva. Liminalne oblasti nisu, ipak, samo ritualno izdvojena mesta inicijacije, već su takva, po Tarneru, i boravišta svojevoljnih otpadnika od sistema i onih koje je sam sistem marginalizovao ili stigmatizovao $i$ učinio inferiornim. One su paradoksalne i ambivalentne jer su istovremeno izolovane i integrisane, i sistemske i anti-sistemske (Turner 1991: 94-96, 102-111). Detaljnije o liminalnosti u Podzemlju, ali u svetlosti interesovanja savremene eko-kritike (Rozelle 2010). 


\section{LITERATURA}

Arden,P.2007. Kontekstualna umetnost: umetničko stvaranje u gradskoj sredini, u situaciji, intervencija, učestvovanje. Novi Sad: Muzej savremene umetnosti Vojvodine.

Bodrijar, Ž. 1991. Simbolička razmena i smrt, prev. M. Marković. Gornji Milanovac: Dečje novine. Churchill, W. 1940. We shall fight on the beaches. [Internet]. Available at: http://www. winstonchurchill.org/learn/speeches/speeches-of-winston-churchill/1940-finesthour/128-we-shall-fight-on-the-beaches [01.02.2014].

De Certeau, M. 1984. The Practice of Everyday Life. Berkeley: Univerity of California Press. DeLilo, D. 2007. Podzemlje, prev. Z.Paunović. Beograd: Geopoetika.

DeLillo, D. 2011. Underworld. London: Picador.

Ethell, J. L. and C. Simonsen. 1991. The History of Aircraft Nose Art: from WWI to Today. Somerset: Haynes Publishing Group.

Farrell, J. 1996. Crimes of Style: Urban Graffiti and the Politics of Criminality. Boston: Northeastern University Press.

Pfau, A. E. 2006. Miss Yourloving: GIs, Gender and Domesticity during World War II. [Internet]. Available at: http://gutenberg-e.org/pfau/chapter4.html [18.12.2012].

Rozelle, L. 2010. Resurveying DeLillo's "White Space on Map": Liminality and Communitas in Underworld. Studies in the Novel 42 (4), 443-452.

Sulima, R. 2005. Antropologija svakodnevice. Beograd: Biblioteka XX vek.

Torg, A. 2002. Pop i rok muzika, prev. I. Mirković. Beograd: Clio.

Turner, V. W. 1977. The Ritual Process: Structure and Anti-Structure. New York: Cornell University Press.

Šuvaković, M. 1999. Pojmovnik moderne i postmoderne likovne umetnosti i teorije posle 1950. godine. Beograd/Novi Sad: SANU/Prometej.

\section{SUMMARY}

\section{GRAFFITI IN DON DELILLO'S UNDERWORLD}

The paper deals with DeLillo's representations and interpretations of various graffiti types in his Underworld. There are several episodes, discussions and accounts of graffiti practices in the novel, so that DeLillo's attitudes toward these practices, their aesthetics and politics, and his view of their relationships with other cultural movements, creative industries and artistic forms and genres are the topic of this research. The influences of these graffiti forms and styles on the work of Clara Sax, as presented in the novel, and her re-interpretation and re-appropriation of graffiti artists' stylistic devices and motivations are accentuated.

KEYWORDS: graffiti, nose art, politics of art, subculture. 